\title{
A school based, interdisciplinary curriculum in grades 6 and 7 reduced obesity in girls
}

\author{
Gortmaker SL, Peterson K, Wiecha J, et al.Reducing obesity via a school-based interdisciplinary intervention among youth. \\ Planet Health. Arch Pediatr Adolesc Med 1999 Apr;153:409-18.
}

QUESTION: Can a school based, interdisciplinary health behaviour curriculum reduce obesity in boys and girls in grades 6 and 7 ?

\section{Design}

Randomised (unclear allocation concealment), controlled, unblinded trial with follow up over 2 school years (Planet Health programme).

\section{Setting}

10 schools in 4 communities in Boston, Massachusetts, USA.

\section{Participants}

1560 students with parental consent who were in grades 6 or 7 (approximately ages 11 and 12 y) on 1 September, 1995 received Planet Health or the usual curriculum; students in special education classes were excluded. 1295 children (mean age 11.7 y, 52\% boys, 69\% white) $(83 \%)$ were evaluated at the end of the study.

\section{Intervention}

5 schools were allocated to the Planet Health programme, which consisted of teacher training workshops, classroom lessons, physical education materials, wellness sessions, and fitness funds. The programme included 32 (16/y) lessons focused on television viewing, activity, and diet provided across 4 subjects: language arts, mathematics, science, and social studies. Teaching methods encouraged active student participation. 5 schools were allocated to the usual health and physical education curricula (control schools).

\section{Main outcome measures}

Obesity defined using body mass index and triceps skinfold value at or above the age and sex specific 85th centile and remission of obesity defined as reduction of obesity among those already obese. Secondary outcomes were hours of television and video viewing, moderate and vigorous physical activity, dietary intake of fruits and vegetables, percentage of energy from fat and saturated fat, and total energy intake.

Sources of funding: National Institutes of Child Health and Human Development; Centers of Disease Control and Prevention.

For correspondence: $\operatorname{Dr} S$ Gortmaker, Planet Health, Department of Health and Social Behavior, Harvard Center for Children's Health, Harvard School of Public Health, 677 Huntington Avenue, Boston, MA 02115, USA Fax +16174323123 .

\section{Main results}

Analysis was by intention to treat. The prevalence of obesity decreased for girls in the intervention schools (odds ratio [OR] 0.47, 95\% CI 0.24 to $0.93, \mathrm{p}=0.03$ ) but not for boys (OR 0.85, CI 0.52 to $1.39, \mathrm{p}=0.48$ ). Girls in the intervention schools also had a higher rate of remission of obesity (OR 2.16, CI 1.07 to 4.35, $\mathrm{p}=0.04$ ). Television and video viewing decreased for girls $(0.58 \mathrm{~h}$ reduction, $\mathrm{p}=0.001)$ and boys $(0.4 \mathrm{~h}$ reduction, $\mathrm{p}<0.001)$ in the intervention schools compared with the control schools. Regression analysis found that each hour of reduction in television viewing among girls in the intervention schools was independently associated with a reduction of obesity prevalence (OR 0.85 , CI 0.75 to $0.97, \mathrm{p}=0.02$ ) and with increased remission of obesity (OR 1.92, CI 1.37 to 2.70, $\mathrm{p}=0.002)$. Girls in the intervention schools ate an average of 0.32 more servings of fruit and vegetables each day $(p=0.003)$ and consumed 575 less $\mathrm{kJ} /$ day of total energy $(\mathrm{p}=0.05)$ than girls in the control schools. The groups did not differ for moderate or vigorous activity levels or total percentage of energy from fat.

\section{Conclusion}

A school based interdisciplinary programme offered in grades 6 and 7 decreased obesity, television and video viewing, and total energy intake and increased consumption of fruit and vegetables in girls.

\section{COMMENTARY}

The study by Gortmaker $e t$ al is important because many children have poor dietary habits, get limited exercise, and watch too much television. ${ }^{12}$ Behaviour patterns set in childhood or adolescence will likely carry over into adulthood. The Planet Health programme evaluated in this study has many attractive features: teacher training, interdisciplinary delivery through 4 different subjects, activities that promote student participation in lessons, a 2 week campaign to reduce television viewing in households, physical education materials focused on activity, and fitness funds.

This study appropriately focuses on behavioural rather than knowledge outcomes. Although children may be able to list the correct dietary facts, they (like adults) often do not turn their knowledge gain into a positive behaviour change. A further strength of the study is the lengthy 2 year follow up of the students. Often behaviour changes are short lived; in this case, we have evidence of a long term benefit.The study weaknesses include self reported diet and physical activity, which have been problematic in other studies. ${ }^{3}$

School nurses are often called upon by teachers to advise them about health programmes to reduce obesity. Planet Health is a multicomponent programme which appears to be effective and which they may wish to consider. Study findings point to a relation between reduced television viewing time and reductions in obesity in girls. The authors note that reduction of television viewing time can be a useful addition to intervention efforts.

Catriona M Kerr, RGN, DN, BTTA
School Nurse
Community Child Health Directorate
Yorkhill NHS Trust
Glasgow, UK

1 Laurence S, Levine A. You and your adolescent: a parents'guide for ages 10 to 20. London, UK: Ebury Press, 1992.

2 National Dairy Council. Teenage eating habits and attitudes. London, UK: Holborn Publishing Group, 1990.

3 Edwards M. Health promotion: maximising bone mass in young women. Journal of Community Practitioner E Health Visitors'Association 1998;71:256-9. 